\title{
Article
}

\section{$\beta$-Cyclodextrin Attenuates Perfluorooctanoic Acid Toxicity in the Zebrafish Embryo Model}

\author{
Mary Jo Weiss-Errico (ㅁ), John P. Berry * and Kevin E. O'Shea * \\ Department of Chemistry and Biochemistry, Florida International University, 11200 SW Eighth Street, \\ Miami, FL 33199, USA; mweis047@fiu.edu \\ * Correspondence: berryj@fiu.edu (J.P.B.); osheak@fiu.edu (K.E.O.); \\ Tel.: +1-305-919-4569 (J.P.B.); +1-305-348-3968 (K.E.O.)
}

Received: 27 September 2017; Accepted: 1 November 2017; Published: 4 November 2017

\begin{abstract}
Perfluorooctanoic acid (PFOA) has been linked to negative health outcomes including cancer, thyroid disease, infertility, and developmental delays. $\beta$-Cyclodextrin $(\beta-C D)$, a cyclic sugar, has been previously shown to form strong host-guest complexes with PFOA, and is proposed as a means of environmental remediation with respect to this widespread contaminant. In the present study, $\beta-C D$ was directly examined with regards to possible attenuation of the toxicity of PFOA specifically employing the zebrafish (Danio rerio) embryo model. Zebrafish embryos were exposed to various concentrations of PFOA without $\beta-C D$, and with equimolar (1:1) and excess (2:1) molar ratios of $\beta-C D$ to PFOA, and assessed for lethality and developmental toxicity through seven days post-fertilization (dpf). Rapid onset of lethality with limited morphological abnormalities was observed at relatively low concentrations of PFOA ( $\left.\mathrm{LC}_{50} \approx 50 \mathrm{ppm}\right)$, along with effects on morphometric and neurobehavioral parameters in surviving embryos. A highly significant difference $(p<0.0001)$ was observed between the 2:1 treatment, and both 1:1 and PFOA only treatments, with respect to lethal concentration and apparent neurobehavioral effects, suggesting an effectively reduced toxicity of the fully complexed PFOA. In contrast, however, neither $\beta$-CD treatment reduced developmental toxicity with respect to the morphometric endpoint (i.e., interocular distance). Whereas $\mathrm{LC}_{50}$ of PFOA alone did not change over $7 \mathrm{dpf}$, the 1:1 and 2:1 values decreased slightly over time, suggesting either delayed or alternative toxic effects on later developmental stages at presumptively lowered levels. This study, therefore, indicates $\beta$-CD may be an effective agent to reduce toxicity of and mitigate environmental health concerns associated with PFOA, but that further study is required to elucidate the mechanism of complexation as it relates to the attenuation of toxicity.
\end{abstract}

Keywords: perfluorooctanoic acid; $\beta$-Cyclodextrin; zebrafish embryo; host-guest chemistry; toxicity

\section{Introduction}

Perfluorooctanoic acid (PFOA) is a persistent organic pollutant and contaminant of emerging concern $[1,2]$. PFOA belongs to a large class of perfluorinated alkyl substances (PFASs). PFOA has been used historically in fluoropolymer synthesis, in aqueous film-forming foams, and in stain-, grease-, and water-repellants for consumer products [1-4]. The structure has seven perfluorinated carbons, and a carboxylic acid head group (Figure 1), making PFOA both hydrophobic and lipophobic. The numerous C-F bonds give the compound extreme chemical and thermal stability $[1,2,5]$. These unique properties cause PFOA to be both environmentally persistent and bioaccumulative [1-8]. Exposure specifically to PFOA has been linked to various cancers, including liver, kidney and bladder cancer, as well as thyroid disease, infertility, and developmental delays [5-13]. Although PFOA has been phased-out of production in the United States and Europe, it is still widely detected in the environment, wildlife, and humans [3-9]. A recent study found that over six million Americans have 
drinking water with PFOA concentrations above the U.S. Environmental Protection Agency's lifetime advisory limit (70 parts per trillion) [4]. There is an urgent need to identify effective methods for environmental remediation, and other mitigation strategies (e.g., water treatment), with respect to the negative health effects of PFOA.

Cyclodextrins (CDs) have been proposed as a remediation strategy for a variety of pollutants, including perfluorinated surfactants such as PFOA [14-22]. Structurally, CDs are cyclic sugars made up of glucose monomers. They are inexpensive, water soluble, and non-toxic, and have been used not only in environmental remediation applications, but also as drug delivery systems for hydrophobic drugs [14-17]. $\beta$-Cyclodextrin $(\beta-C D)$, made up of seven glucose monomers, has been shown to strongly encapsulate PFOA to form one of the strongest known CD-based host-guest complexes [18-26]. The fully fluorinated backbone of the PFOA alkyl chain interacts with the hydrophobic $\beta$-CD cavity via van der Waals interactions, while the PFOA carboxylate group can form hydrogen bonds with hydroxyl groups lining the cavity perimeter of $\beta$-CD (Figure 1). Furthermore, the $\beta$-CD cavity has an ideal cross-sectional area $\left(30.2 \AA^{2}\right)$ to encapsulate PFOA $\left(28.3 \AA^{2}\right)$ [18]. Both $1: 1$ and 2:1 $\beta$-CD:PFOA complexes (Figure 1) are formed in solution, with association constants of $5.0 \times 10^{5}$ and $1.2 \times 10^{3} \mathrm{M}^{-1}$, respectively [18]. In a 1:1 ratio, the $\beta$-CD complexes at the middle of the PFOA backbone, whereas, at the 2:1 ratio, almost the full length of the PFOA chain is encapsulated by two adjacent $\beta$-CDs [18]. Since the encapsulation is strong, the presence of $\beta-C D$ in PFOA-contaminated aqueous media dramatically reduces the concentration of uncomplexed PFOA, and, thus, is expected to inhibit its toxic effects.

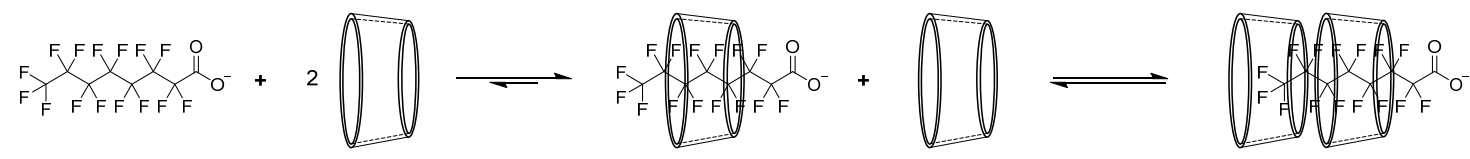

Figure 1. Host-guest complexes of $\beta$-cyclodextrin $(\beta-C D)$ and perfluorooctanoic acid (PFOA), and equilibrium from free PFOA to the 1:1 $\beta$-CD:PFOA complex to the 2:1 $\beta$-CD:PFOA complex (from left to right). Cross-sectional areas of PFOA and $\beta-C D$, respectively, are $28.3 \AA^{2}$ and $30.2 \AA^{2}$ [18].

To assess the potential of $\beta-C D$ to attenuate the developmental and lethal effects of PFOA, we utilized the zebrafish (Danio rerio) embryo as a toxicological model. The zebrafish, and particularly embryonic and larval stages, have emerged as an important model system in a wide range of fields including assessment of chemical toxicity $[27,28]$. Practical advantages of the zebrafish embryo system include ease of rearing and a high fecundity, as well as small $(\sim 1 \mathrm{~mm})$ and nearly transparent embryos, rapid ( $\leq 5-7$ day) embryo development, and a fully sequenced genome. As such, the zebrafish embryo has been employed to look at a wide range of environmental contaminants in terms of acute and chronic toxicity [29-31]. Acute toxicological endpoints (e.g., embryotoxicity, teratogenicity, neurotoxicity), which are readily accessible in the zebrafish embryo model, are, furthermore, aligned with the reported health concerns associated with PFOA, and the system has, indeed, been used to evaluate toxicity of PFOA and related perfluorinated alkyl substances [32-40].

We propose that the $\beta$-CD:PFOA complex will effectively reduce the toxicity of PFOA in the zebrafish embryo. To test this hypothesis, relevant metrics of toxicity (e.g., lethal concentrations, developmental impairment, and neurobehavioral effects) were assessed for PFOA alone, and in the presence of equimolar (1:1) and excess $(2: 1) \beta-C D$. The goal of the study was to evaluate potential reduction of toxicity in relation to complex formation. Although various human health effects have been linked to much lower environmental concentrations, relatively high concentrations of PFOA (i.e., parts-per-million ( $\mathrm{ppm}$ ) levels) were used in the current study rather than environmentally relevant concentrations such that acute toxicological endpoints, as a proxy of PFOA toxicity, could be assessed. This study, therefore, provides direct insight into the potential utility of cyclodextrins for attenuating the toxic effects of PFOA, and, thus, a key step toward future development of $\beta$-CD as a tool for mitigating the health effects associated with PFOA. 


\section{Materials and Methods}

\subsection{Test Chemicals}

Perfluorooctanoic acid (PFOA, 96\% purity) was purchased from Sigma-Aldrich (St. Louis, MO, USA). $\beta$-Cyclodextrin ( $\beta-C D, 98 \%$ purity) was purchased from Acros Organics (Geel, Belgium). Both chemicals were used without further purification. Stock solutions of PFOA (7.25 mM, i.e., 3000 parts-per-million (ppm)), 1:1 $\beta$-CD:PFOA ( $\beta$-CD: 7.25 mM, PFOA: $7.25 \mathrm{mM}$ ), and 2:1 $\beta$-CD:PFOA ( $\beta$-CD: $14.50 \mathrm{mM}$, PFOA: $7.25 \mathrm{mM}$ ) were prepared with deionized water in polypropylene tubes. The solutions were sonicated until dissolution of the solids was achieved. A control solution of deionized water was also stored in a polypropylene tube. Stock solutions were subsequently diluted over a relevant range of concentrations (see below) for assessment of zebrafish embryo toxicity.

\subsection{Zebrafish Rearing and Breeding}

To obtain embryos, zebrafish (PS strain) were reared and bred as previously described [41,42]. Briefly, adult zebrafish were maintained in 30-L tanks at $28^{\circ} \mathrm{C}$ with $14 \mathrm{~h}: 10 \mathrm{~h} \mathrm{light} /$ dark cycle, and bred (from approximately 10-30 individuals) above 10-L tanks in mesh enclosures. Eggs were collected (from the bottom of tanks) within $1 \mathrm{~h}$ of the end of the dark cycle, and, following collection and washing, transferred to plates containing E3 medium [43]. Eggs containing dead, or obviously poor quality embryos, were removed. The remaining embryos were used, within $\sim 2 \mathrm{~h}$ post-fertilization (hpf), for toxicity assays. All rearing and breeding was conducted under protocols approved by the University of Miami's Institutional Animal Care and Use Committee (IACUC), and performed by trained investigators.

\subsection{Zebrafish Embryo Toxicity Assay}

Zebrafish embryo toxicity assays were adapted from previously described methods [41,42]. Assays were conducted in polypropylene 24-well plates (Evergreen Scientific, Los Angeles, CA, USA) with five embryos (4- to 32-cell stage) per replicate, i.e., well $(n=4)$, in E3 medium for a total of 20 zebrafish embryos per treatment/concentration [43]. Embryos were exposed via static exposure (i.e., without replenishment) to a range of PFOA concentrations (30, 50, 100, 150, 200, 250 and $300 \mathrm{ppm}$ ) alone, and in 1:1 and 2:1 ratios with $\beta-C D$, and subsequently observed at 1, 2, 3, 4 and 7 days post-fertilization (dpf) with a dissecting light microscope to assess mortality and relevant developmental toxicity. Exposures and assessments were repeated several times, in preliminary studies, to determine relevant concentration levels for PFOA, and generally confirm results. Lethality was calculated as the concentration corresponding to 50\% mortality $\left(\mathrm{LC}_{50}\right)$; the $\mathrm{LC}_{50}$ values, and their $95 \%$ confidence intervals, were calculated via Probit Analysis in SPSS (version 22.0; IBM Corporation, Armonk, NY, USA, 2013) [44]. In addition to lethality, inhibition of embryo development was morphometrically assessed based on the interocular distance between eyes (as a proxy for body size) of $7 \mathrm{dpf}$ embryos (i.e., eleuthero-embryo stage) as measured using Olympus DP2-BSW imaging software (Olympus, Center Valley, PA, USA, 2009). Apparent neurobehavioral effects were additionally measured as the percent of 7-dpf eleuthero-embryos displaying listing (i.e., falling to one side) behavior within a $30 \mathrm{~s}$ period (with shaking between each measurement to allow embryos to right themselves). All toxicity assays involving zebrafish were conducted under protocols approved by the Florida International University's Institutional Animal Care and Use Committee (IACUC), and performed by trained investigators.

\subsection{Statistical Analyses}

One-way analysis of variance (ANOVA) of the $\mathrm{LC}_{50}$ values, as well as the interocular distance and percent listing at $7 \mathrm{dpf}$, was performed in GraphPad Prism (version 5.03; GraphPad Software, Inc., La Jolla, CA, USA, 2010.) [45]. The significance level was set at $p=0.05$. 


\section{Results}

\subsection{PFOA Toxicity in the Zebrafish Embryo Model}

A rapid onset of embryotoxicity was observed for PFOA with mortality, characterized by coagulation of embryos, occurring within a few hours of exposure. By $24 \mathrm{hpf}$, a significant dose-dependent response with respect to lethality was observed (Figure 2) with all embryos dead at PFOA concentrations above 100 ppm. The observed dose response, with respect to mortality, remained largely unchanged, and the calculated $\mathrm{LC}_{50}$ values did not significantly change over the course of the exposure (i.e., 7 dpf; Figure 3). Notably, aside from a higher number of mortalities, no clear pattern of developmental deformities was observed: by $7 \mathrm{dpf}$, for example, only 5\% of both control and PFOA-treated embryos showed any discernible deformities, which included bent spines and edemas. Similarly, the hatching rates were unaffected with the majority of surviving embryos, in both control and PFOA treatments, hatched by $3 \mathrm{dpf}$.

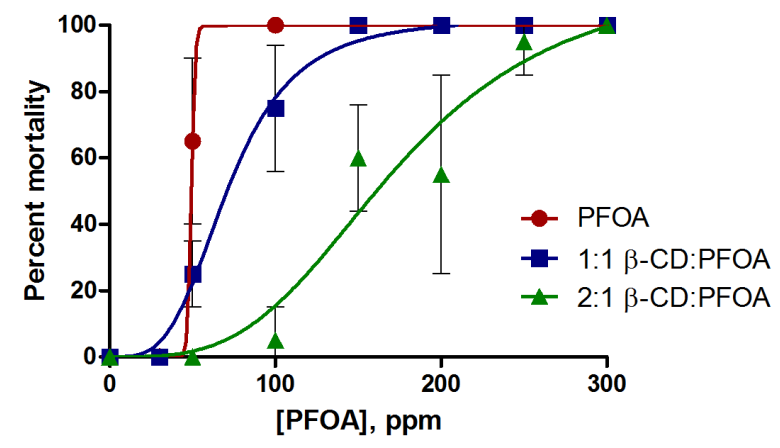

Figure 2. Concentration dependent toxicity of PFOA, and 1:1 and 2:1 $\beta-C D$ : PFOA treatments, in terms of rapid onset lethality. Shown is percent mortality at $24 \mathrm{~h}$ post-fertilization (hpf) (error bars represent \pm one standard deviation, $n=4)$.

Apparent inhibition of embryo growth (i.e., reduced body size), however, was observed, with the surviving PFOA-treated embryos being smaller at the end of the exposure (i.e., $7 \mathrm{dpf}$ ) compared to controls. Inhibition of development was specifically evaluated morphometrically based on interocular distance at $7 \mathrm{dpf}$ : significantly $(p<0.0001)$ reduced interocular distances were measured for surviving PFOA-treated embryos at sub-lethal concentrations (i.e., $\leq 50 \mathrm{ppm}$, pooled; $0.25 \pm 0.06 \mathrm{~mm}$ ) versus untreated control $(0.41 \pm 0.14 \mathrm{~mm}$ ) embryos (Figure 4$)$. In terms of other relevant endpoints, apparent neurobehavioral effects were observed for surviving embryos, and specifically a high frequency of listing was observed for PFOA-treated embryos. At low PFOA concentrations below the LC 50 (i.e., $\leq 50 \mathrm{ppm}$, pooled), the percent of surviving embryos observed to list within a $30 \mathrm{~s}$ period $(96 \pm 9 \%)$ was significantly higher $(p<0.0001)$ than controls without PFOA $(20 \pm 13 \%$; Figure 5).

\subsection{Attenuation of PFOA Toxicity by $\beta-C D$}

To evaluate the ability of $\beta-C D$ to reduce the toxicity of PFOA, the $\mathrm{LC}_{50}$ values for each treatment (PFOA alone, 1:1 and 2:1 $\beta$-CD:PFOA ratios) were calculated and compared. At $1 \mathrm{dpf}$, a significantly (ANOVA, $p<0.0001$ ) higher LC $_{50}$ was observed for 2:1 $\beta$-CD:PFOA $(159.3 \pm 22.9$ ppm) compared to both PFOA alone $(47.3 \pm 3.6 \mathrm{ppm})$, and the 1:1 $\beta$-CD:PFOA treatment (69.9 $\pm 5.7 \mathrm{ppm})$. The lethal concentration for 1:1 $\beta$-CD:PFOA was higher than PFOA alone, but the difference was not statistically significant. However, whereas $\mathrm{LC}_{50}$ did not change over time for PFOA alone, calculated values for both 1:1 and 2:1 $\beta$-CD:PFOA treatments notably decreased over 7 days of exposure (Figure 3) due to additional, post-hatch mortalities. By $4 \mathrm{dpf}$, the 1:1 $\beta$-CD:PFOA LC 50 (48.1 \pm 14.2 ppm) was essentially equal to the PFOA alone. Although LC $_{50}$ for 2:1 $\beta$-CD:PFOA treatment decreased (e.g., $80.5 \pm 9.3$ ppm by $7 \mathrm{dpf})$, it was still significantly $(p<0.0001)$ higher than either PFOA alone, or PFOA 
in a 1:1 ratio with $\beta-C D$. No discernible toxicity was observed for $\beta-C D$ alone, within the range of tested concentrations, including the maximum concentration (i.e., $1645 \mathrm{ppm}$, or $1.45 \mathrm{mM}, \beta-\mathrm{CD}$ ) evaluated in the $2: 1$ ratio treatments.

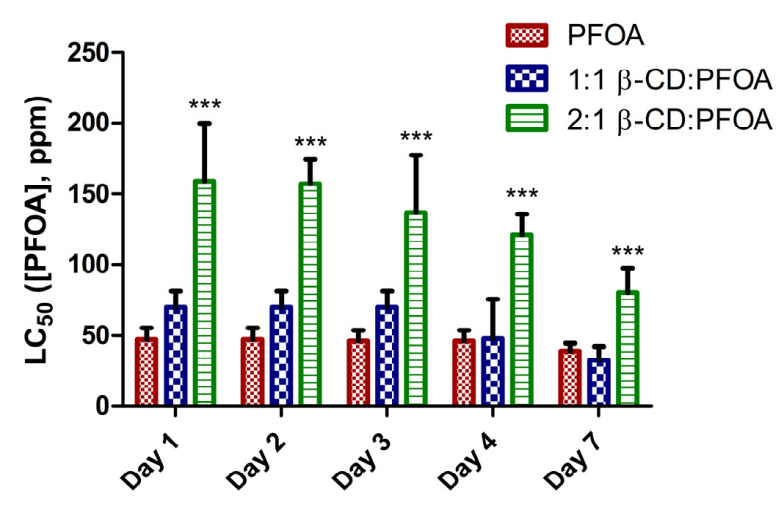

Figure 3. Calculated 50\% lethal concentration $\left(\mathrm{LC}_{50}\right)$ values for PFOA only, 1:1 $\beta$-CD:PFOA,

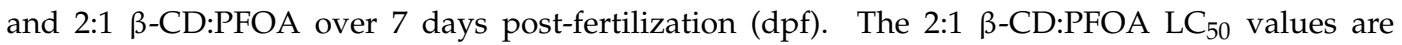
significantly different $(* * *=p<0.0001)$ than PFOA only, and 1:1 $\beta$-CD:PFOA. The $\mathrm{LC}_{50}$ values for PFOA only and 1:1 $\beta$-CD:PFOA are not significantly different from each other. Error bars represent $95 \%$ confidence intervals.

In contrast to lethality, $\beta-\mathrm{CD}$ did not reduce apparent developmental toxicity in terms of a morphometric variable, i.e., interocular distance (Figure 4). Comparing surviving embryos at, or below, the $\mathrm{LC}_{50}$ (i.e., $\leq 50 \mathrm{ppm}$ ), the measure of interocular distance for $7 \mathrm{dpf}$ embryos was significantly $(p<0.0001)$ lower in both 1:1 $\beta$-CD:PFOA $(0.25 \pm 0.07 \mathrm{~mm})$ and 2:1 $\beta$-CD:PFOA $(0.29 \pm 0.07 \mathrm{~mm})$ treatments when compared to controls, and nearly identical to PFOA alone (see above). Similar to lethality, on the other hand, the apparent neurobehavioral effect (i.e., listing) among $7 \mathrm{dpf}$ embryos was reduced among surviving embryos at sub-lethal concentrations (i.e., $\leq 50 \mathrm{ppm}$ ) in the 2:1 $\beta$-CD:PFOA treatment: percent listing in this treatment was not significantly different from untreated controls (Figure 5). Frequency of listing in the 1:1 treatment was decreased, compared to that of PFOA alone, but it was still significantly higher $(p<0.01)$ than untreated controls.

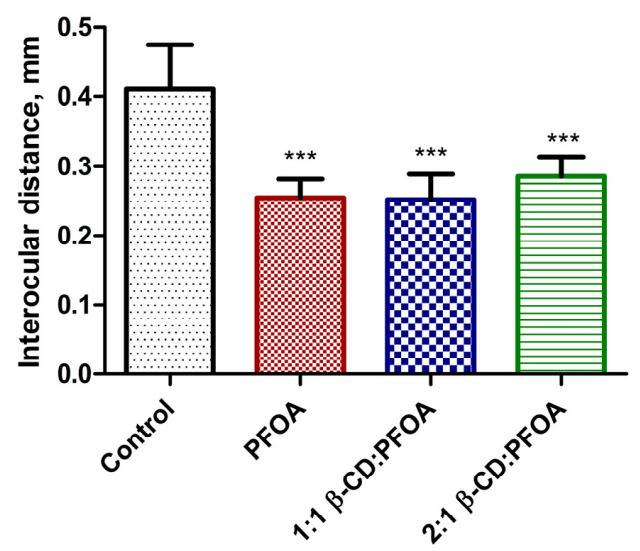

Figure 4. Interocular distance, as a morphometric measure of embryo body size, for untreated embryos ("Control") compared to surviving embryos in sub-lethal concentrations ( $\leq 50 \mathrm{ppm}$ ) of PFOA only, and 1:1 and 2:1 $\beta$-CD:PFOA treatments, at $7 \mathrm{dpf}$. All three treatments are significantly different $\left(^{* * *}=p<0.0001\right)$ than controls. The three treatments are not significantly different from each other. Error bars represent $95 \%$ confidence intervals. 


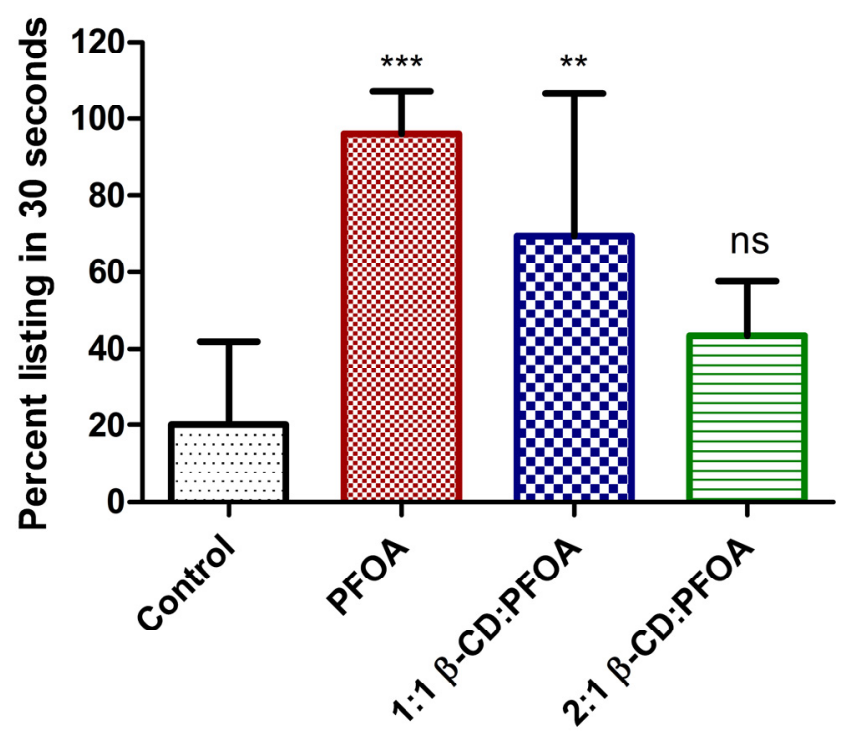

Figure 5. Percent listing after $30 \mathrm{~s}$ for the untreated embryos ("Control") compared to surviving embryos in sub-lethal concentrations ( $\leq 50 \mathrm{ppm}$ ) of PFOA only, and 1:1 and 2:1 $\beta$-CD:PFOA treatments, at $7 \mathrm{dpf}$. The control values are significantly different from PFOA only $\left.{ }^{* * *}=p<0.0001\right)$ and 1:1 $\beta$-CD:PFOA $(* *=p<0.01)$. The $2: 1 \beta$-CD:PFOA values were not significantly different from controls ("ns"). Error bars represent $95 \%$ confidence intervals.

\section{Discussion}

Toxicity of PFOA in the zebrafish embryo model, including embryotoxicity (i.e., lethality), reduced body size, and neurobehavioral effects observed in the present study, is generally consistent with prior studies [32,33,35]. Aligned with these previous studies [33], a rapid onset of lethality ( $\leq 24 \mathrm{hpf}$ ), and relatively limited occurrence of developmental deformities, including bent spines and edemas were similarly observed in the current study. Lethal concentrations for PFOA (i.e., $\mathrm{LC}_{50} \approx 50 \mathrm{ppm}$; Figure 3) in the current study, however, were considerably lower than measured in prior studies, which have typically reported $\mathrm{LC}_{50}$ values above $500 \mathrm{ppm}$ and/or test ranges [32,40], although others [33,35] have reported somewhat lower values (e.g., 262 and 371 ppm, respectively). It has been suggested [37] that the $\mathrm{LC}_{50}$ of PFOA may be, in fact, ten times lower than originally reported, which would put it within the range presently observed. Variability in lethal concentrations is presumably due to genetic differences of zebrafish lines used and/or other experimental conditions, and were not addressed further in the present study. Both reduced body size (Figure 4) and locomotory effects (Figure 5) have been, likewise, reported for PFOA-treated zebrafish embryos at sub-lethal concentrations [32,37-39]. Notably, these sub-lethal effects were observed in previous studies $[38,39]$ at considerably lower (i.e., micro- to nanomolar) exposure concentrations, and, interestingly, effects extended into (following embryonic exposure) adult stages.

Consistent with formation of host-guest complexes, $\beta$-CD generally reduced toxicity of PFOA (Figures 3 and 5). Although a 1:1 ratio decreased both rapid lethality at early embryonic stages (i.e., $\leq 3 \mathrm{dpf}$ ), and neurobehavioral effects, only the measured decreases (approximately two-fold) associated with the 2:1 ratio were statistically significant through $7 \mathrm{dpf}$ (Figure 3). That being said, neither $\beta-\mathrm{CD}$ treatment significantly attenuated a morphometric variable (interocular distance) indicative of reduced embryo growth and body size associated with PFOA toxicity (Figure 4). Furthermore, while the $\mathrm{LC}_{50}$ of PFOA alone did not change during the exposure, values decreased over $7 \mathrm{dpf}$ for both 1:1 and 2:1 ratios (Figure 3). These latter observations suggest a toxicity toward post-hatch larvae at either presumably lowered concentrations of non-complexed PFOA or alternatively less toxic and/or bioavailable complexes, which are uncoupled from the potent embryotoxicity associated with rapid onset lethality at early embryonic stages. 
The mechanism whereby $\beta-C D$ reduces toxicity via complex formation remains to be clarified in future studies. However, the current state of knowledge with respect to the formation of the $\beta$-CD:PFOA host-guest complex points to a few possibilities. It appears that the ratio of $\beta$-CD, rather than the concentration of $\beta-C D$, determines the inhibition of PFOA toxicity. Previous studies have shown that, at equimolar concentrations, PFOA is strongly complexed by $\beta-C D$ with a 1:1 $\beta-C D: P F O A$ association constant of $5.0 \times 10^{5} \mathrm{M}^{-1}$, and, furthermore, suggest that the complex is not significantly disturbed under different water quality conditions (e.g., ionic strength, $\mathrm{pH}$, presence of humic acid, and presence of competing model pollutants) [18]. In addition, a 2:1 complex can form (Figure 1), particularly in the presence of excess $\beta-C D$ (as expected in the 2:1 ratio treatment). Differences in bioavailability, and thus uptake, of the two complexes, may explain the differential toxicity observed between 1:1 and 2:1 $\beta-C D$ treatments. Indeed, it has been shown that relative lipophilicity significantly effects and is correlated with uptake in the zebrafish embryo model [46]. It would be expected that increased complexation of PFOA would decrease $\log P$ values and, thus, uptake.

This model (Figure 1), however, largely assumes stoichiometric, stepwise and stable host-guest complexes. Alternatively, it is possible that non-stoichiometric and/or non-sequential complex formation could lead to, likewise, non-stoichiometrically reduced levels of free PFOA which would, in turn, be quantitatively dependent on the relative $\beta-C D$ concentration. Such an alternative model could, therefore, explain quantitative differences in toxicity between 1:1 and 2:1 ratios whereby, for example, formation of "2:1 complexes" under equimolar (1:1) conditions would lead to persistence of uncomplexed (and thus toxic) PFOA. Presence of free PFOA in solution, and corresponding sub-lethal toxicity might, in this regard, be further exacerbated by bioaccumulation of PFOA, and subsequent release at later stages. Indeed, previous studies have shown high levels of bioconcentration of PFOA in zebrafish embryos including intestine and bile (and potential enterohepatic recirculation), as well as yolk, as a means of bioaccumulation and release at later embryonic stages [36]. Competition between bioaccumulation and complex formation might, more generally, explain toxicity at higher concentrations even in 2:1 treatments including both post-hatch toxicity (Figure 3), and inability of either $\beta$-CD treatment to effectively reduce developmental toxicity, in terms of morphometric parameters (Figure 4). Quantitative analysis of PFOA and $\beta-C D$ complexes with respect to both exposure medium and bioaccumulation/uptake (e.g., critical body residue), including tissue specific bioavailability, in future studies could address these interrelated mechanisms.

\section{Conclusions}

The results of this study directly suggest that $\beta-C D$, particularly in excess molar ratios, can largely attenuate the toxicity of PFOA in solution as evidenced by reduced toxicity in the zebrafish embryo model. The ratio of $\beta-C D$ to PFOA, rather than the concentration of $\beta-C D$, drives this attenuation. It is proposed that the host-guest complex may exhibit less biological activity, or alter bioavailability, compared to PFOA alone. Alternatively, $\beta$-CD may simply reduce by way of the variable formation of 1:1 and 2:1 complexes levels of free (and thus toxic) PFOA in solution in a concentration-dependent manner. Further research is needed to understand the mechanism of decreased toxicity, as well as to determine efficacy of $\beta-C D$ at environmentally relevant concentrations of PFOA, and with respect to non-acute toxicological endpoints (specifically relevant to human health). However, these findings suggest that $\beta-C D$ is a potentially promising tool for environmental remediation, and mitigation of toxic effects (e.g., drinking water treatment), of PFOA and, perhaps, related perfluorinated compounds as they relate to environmental health concerns.

Acknowledgments: The authors would like to thank Pat Gibbs from University of Miami Rosenstiel School of Marine and Atmospheric Science for providing zebrafish embryos used in this study. The authors also gratefully acknowledge support from Florida International University's Presidential Fellowship program, which financially supported, in part, M.J.W.-E.

Author Contributions: M.J.W.-E., J.P.B, and K.E.O. conceived and designed the experiments; M.J.W.-E. performed the experiments and analyzed the data; M.J.W.-E., J.P.B., and K.E.O. wrote the paper. 
Conflicts of Interest: The authors declare no conflict of interest.

\section{References}

1. Prevedouros, K.; Cousins, I.T.; Buck, R.C.; Korzeniowski, S.H. Source, fate, and transport of perfluorocarboxylates. Environ. Sci. Technol. 2006, 40, 32-44. [CrossRef] [PubMed]

2. Wang, Z.; DeWitt, J.C.; Higgins, C.P.; Cousins, I.T. A never-ending story of per- and polyfluoroalkyl substances (PFASs)? Environ. Sci. Technol. 2017, 51, 2508-2518. [CrossRef] [PubMed]

3. Schaider, L.A.; Balan, S.A.; Blum, A.; Andrews, D.Q.; Strynar, M.J.; Dickinson, M.E.; Lunderberg, D.M.; Lang, J.R.; Peaslee, G.F. Fluorinated compounds in U.S. fast food packaging. Environ. Sci. Technol. Lett. 2017, 4, 105-111. [CrossRef]

4. Barzen-Hanson, K.A.; Roberts, S.C.; Choyke, S.; Oetjen, K.; McAlees, A.; Riddell, N.; McCrindle, R.; Ferguson, P.L.; Higgins, C.P.; Field, J.A. Discovery of 40 classes of per- and polyfluoroalkyl substances in historical aqueous film-forming foams (AFFFs) and AFFF-impacted groundwater. Environ. Sci. Technol. 2017, 51, 2047-2057. [CrossRef] [PubMed]

5. Jensen, A.A.; Leffers, H. Emerging endocrine disrupters: Perfluoroalkylated substances. Int. J. Androl. 2008, 31, 161-169. [CrossRef] [PubMed]

6. Kannan, K. Perfluoroalkyl and polyfluoroalkyl substances: Current and future perspectives. Environ. Chem. 2011, 8, 333-338. [CrossRef]

7. Houde, M.; Martin, J.W.; Letcher, R.J.; Solomon, K.R.; Muir, D.C.G. Biological monitoring of polyfluoroalkyl substances: A review. Environ. Sci. Technol. 2006, 40, 3463-3473. [CrossRef] [PubMed]

8. D'Hollander, W.; de Voogt, P.; Coen, W.D.; Bervoets, L. Perfluorinated substances in human food and other sources of human exposure. Rev. Environ. Contam. Toxicol. 2010, 208, 179-215. [CrossRef] [PubMed]

9. Pérez, F.; Nadal, M.; Navarro-Ortega, A.; Fàbrega, F.; Domingo, J.L.; Barceló, D.; Farré, M. Accumulation of perfluoroalkyl substances in human tissues. Environ. Int. 2013, 59, 354-362. [CrossRef] [PubMed]

10. Frisbee, S.J.; Brooks, A.P.; Maher, A.; Flensborg, P.; Arnold, S.; Fletcher, T.; Steenland, K.; Shankar, A.; Knox, S.S.; Pollard, C.; et al. The C8 health project: Design, methods, and participants. Environ. Health Perspect. 2009, 117, 1873-1882. [CrossRef] [PubMed]

11. Barry, V.; Winquist, A.; Steenland, K. Perfluorooctanoic acid (PFOA) exposures and incident cancers among adults living near a chemical plant. Environ. Health Perspect. 2013, 121, 1313-1318. [CrossRef] [PubMed]

12. Vieira, V.M.; Hoffman, K.; Shin, H.M.; Weinberg, J.M.; Webster, T.F.; Fletcher, T. Perfluorooctanoic acid exposure and cancer outcomes in a contaminated community: A geographic analysis. Environ. Health Perspect. 2013, 121, 318-323. [CrossRef] [PubMed]

13. Lopez-Espinosa, M.J.; Mondal, D.; Armstrong, B.; Bloom, M.S.; Fletcher, T. Thyroid function and perfluoroalkyl acids in children living near a chemical plant. Environ. Health Perspect. 2012, 120, 1036-1041. [CrossRef] [PubMed]

14. Crini, G. Recent developments in polysaccharide-based materials used as adsorbents in wastewater treatment. Prog. Polym. Sci. 2005, 30, 38-70. [CrossRef]

15. Del Martin Valle, E.M. Cyclodextrins and their uses: A review. Process Biochem. 2004, 39, $1033-1046$. [CrossRef]

16. Crini, G.; Morcellet, M. Synthesis and applications of adsorbents containing cyclodextrins. J. Sep. Sci. 2002, 25, 789-813. [CrossRef]

17. Morin-Crini, N.; Crini, G. Environmental applications of water-insoluble $\beta$-cyclodextrin-epichlorohydrin polymers. Prog. Polym. Sci. 2013, 38, 344-368. [CrossRef]

18. Weiss-Errico, M.J.; O'Shea, K.E. Detailed NMR investigation of cyclodextrin-perfluorinated surfactant interactions in aqueous media. J. Hazard. Mater. 2017, 329, 57-65. [CrossRef] [PubMed]

19. Karoyo, A.B.; Wilson, L.D. Tunable macromolecular-based materials for the adsorption of perfluorooctanoic and octanoic acid anions. J. Colloid Interface Sci. 2013, 402, 196-203. [CrossRef] [PubMed]

20. Karoyo, A.H.; Wilson, L.D. Nano-sized cyclodextrin-based molecularly imprinted polymer adsorbents for perfluorinated compounds-A mini review. Nanomaterials 2015, 5, 981-1003. [CrossRef] [PubMed]

21. Karoyo, A.H.; Wilson, L.D. Investigation of the adsorption processes of fluorocarbon and hydrocarbon anions at the solid-solution interface of macromolecular imprinted polymer materials. J. Phys. Chem. C 2016, 120, 6553-6568. [CrossRef] 
22. Xiao, L.; Ling, Y.; Alsbaiee, A.; Li, C.; Helbling, D.E.; Dichtel, W.R. $\beta$-Cyclodextrin polymer network sequesters perfluorooctanoic acid at environmentally relevant concentrations. J. Am. Chem. Soc. 2017, 139, 7689-7692. [CrossRef] [PubMed]

23. Wilson, L.D.; Verrall, R.E. ${ }^{19} \mathrm{~F}$ and ${ }^{1} \mathrm{H}-\mathrm{NMR}$ investigation of cyclodextrin/fluorocarbon alkyl carboxylate surfactant inclusion complexes. Langmuir 1998, 14, 4710-4717. [CrossRef]

24. Karoyo, A.H.; Borisov, A.S.; Wilson, L.D.; Hazendonk, P. Formation of host-guest complexes of $\beta$-cyclodextrin and perfluorooctanoic acid. J. Phys. Chem. B 2011, 115, 9511-9527. [CrossRef] [PubMed]

25. Karoyo, A.H.; Sidhu, P.; Wilson, L.D.; Hazendonk, P. Characterization and Dynamic Properties for the Solid Inclusion Complexes of $\beta$-Cyclodextrin and Perfluorooctanoic Acid. J. Phys. Chem. B 2013, 117, 8269-8282. [CrossRef] [PubMed]

26. Karoyo, A.H.; Sidhu, P.S.; Wilson, L.D.; Hazendonk, P.; Borisov, A. Counterion anchoring effect on the structure of the solid-state inclusion complexes of $\beta$-cyclodextrin and sodium perfluorooctanoate. J. Phys. Chem. C 2015, 119, 22225-22243. [CrossRef]

27. Yang, L.; Ho, N.Y.; Alshut, R.; Legradi, J.; Weiss, C.; Reischl, M.; Mikut, R.; Liebel, U.; Müller, F.; Strähle, U. Zebrafish embryos as models for embryotoxicity and teratological effects of chemicals. Reprod. Toxicol. 2009, 28, 245-253. [CrossRef] [PubMed]

28. Planchart, A.; Mattingly, C.J.; Allen, D.; Ceger, P.; Casey, W.; Hinton, D.; Kanungo, J.; Kullman, S.W.; Tal, T.; Bondesson, M.; et al. Advancing toxicology research using in vivo high throughput toxicology with small fish models. ALTEX 2016, 33, 435-452. [CrossRef] [PubMed]

29. Hinton, D.E.; Kullman, S.W.; Hardman, R.C.; Volz, D.C.; Chen, P.J.; Carney, M.; Bencic, D.C. Resolving mechanisms of toxicity while pursuing ecotoxicological relevance? Mar. Pollut. Bull. 2005, 51, 635-648. [CrossRef] [PubMed]

30. Scholz, S.; Fischer, S.; Gündel, U.; Küster, E.; Luckenbach, T.; Voelker, D. The zebrafish embryo model in environmental risk assessment-Applications beyond acute toxicity testing. Environ. Sci. Pollut. Res. Int. 2008, 15, 394-404. [CrossRef] [PubMed]

31. Sarmah, S.; Marrs, J.A. Zebrafish as a vertebrate model system to evaluate effects of environmental toxicants on cardiac development and function. Int. J. Mol. Sci. 2016, 17, 2123. [CrossRef] [PubMed]

32. Hagenaars, A.; Vergauwen, L.; De Coen, W.; Knapen, D. Structure-activity relationship assessment of four perfluorinated chemicals using a prolonged zebrafish early life stage test. Chemosphere 2011, 82, 764-772. [CrossRef] [PubMed]

33. Zheng, X.M.; Liu, H.L.; Shi, W.; Wei, S.; Giesy, J.P.; Yu, H.X. Effects of perfluorinated compounds on development of zebrafish embryos. Environ. Sci. Pollut. Res. Int. 2011, 19, 2498-2505. [CrossRef] [PubMed]

34. Hagenaars, A.; Vergauwen, L.; Benoot, D.; Laukens, K.; Knapen, D. Mechanistic toxicity study of perfluorooctanoic acid in zebrafish suggests mitochondrial dysfunction to play a key role in PFOA toxicity. Chemosphere 2013, 91, 844-856. [CrossRef] [PubMed]

35. Ding, G.; Zhang, J.; Chen, Y.; Wang, L.; Wang, M.; Xiong, D.; Sun, Y. Combined effects of PFOS and PFOA on zebrafish (Danio rerio) embryos. Arch. Environ. Contam. Toxicol. 2013, 64, 668-675. [CrossRef] [PubMed]

36. Ulhaq, M.; Sundström, M.; Larsson, P.; Gabrielsson, J.; Bergman, A.; Norrgren, L.; Örn, S. Tissue uptake, distribution and elimination of (14)C-PFOA in zebrafish (Danio rerio). Aquat. Toxicol. 2015, 163, $148-157$. [CrossRef] [PubMed]

37. Jantzen, C.E.; Annunziato, K.A.; Bugel, S.M.; Cooper, K.R. PFOS, PFNA, and PFOA sub-lethal exposure to embryonic zebrafish have different toxicity profiles in terms of morphometrics, behavior and gene expression. Aquat. Toxicol. 2016, 175, 160-170. [CrossRef] [PubMed]

38. Jantzen, C.E.; Annunziato, K.M.; Cooper, K.R. Behavioral, morphometric, and gene expression effects in adult zebrafish (Danio rerio) embryonically exposed to PFOA, PFOS and PFNA. Aquat. Toxicol. 2016, 180, 123-130. [CrossRef] [PubMed]

39. Jantzen, C.E.; Toor, F.; Annunziato, K.A.; Cooper, K.R. Effects of chronic perfluorooctanoic acid (PFOA) at low concentrations on morphometrics, gene expression, and fecundity in zebrafish (Danio rerio). Reprod. Toxicol. 2017, 69, 34-42. [CrossRef] [PubMed]

40. Rainieri, S.; Conlledo, N.; Langerholc, T.; Madorran, E.; Sala, M.; Barranco, A. Toxic effects of perfluorinated compounds at human cellular level and on a model vertebrate. Food Chem. Toxicol. 2017, 104, 14-25. [CrossRef] [PubMed] 
41. Berry, J.P.; Gantar, M.; Gibbs, P.D.; Schmale, M.C. The zebrafish (Danio rerio) embryo as a model system for identification and characterization of developmental toxins from marine and freshwater microalgae. Comp. Biochem. Physiol. C Toxicol. Pharmacol. 2007, 145, 61-72. [CrossRef] [PubMed]

42. Jaja-Chimedza, A.; Sanchez, K.; Gantar, M.; Gibbs, P.; Schmale, M.C.; Berry, J.P. Carotenoid glycosides from cyanobacteria are teratogenic in the zebrafish (Danio rerio) embryo model. Chemosphere 2017, 174, 478-489. [CrossRef] [PubMed]

43. Brand, M.; Granato, M.; Nüsslein-Volhard, C. Keeping and raising zebrafish. In Zebrafish; Nüsslein-Volhard, C., Dahm, R., Eds.; Oxford University Press: Oxford, UK, 2002; pp. 7-37.

44. International Business Machines Corporation (IBM Corp.). SPSS Statistics, version 22.0; IBM Corp.: Armonk, NY, USA, 2013.

45. GraphPad Software, Inc. Prism 5, version 5.03; GraphPad Software, Inc.: La Jolla, CA, USA, 2010.

46. De Koning, C.; Beekhuijzen, M.; Tobor-Kaplon, M.; de Vries-Buitenweg, S.; Schoutsen, D.; Leeigen, N.; van de Waart, B.; Emmen, H. Visualizing compound distribution during zebrafish embryo development: The effects of lipophilicity and DMSO. Birth Defects Res. B Dev. Reprod. Toxicol. 2015, 104, 253-272. [CrossRef] [PubMed]

(C) 2017 by the authors. Licensee MDPI, Basel, Switzerland. This article is an open access article distributed under the terms and conditions of the Creative Commons Attribution (CC BY) license (http://creativecommons.org/licenses/by/4.0/). 